\title{
Bronchial mucus properties in lung cancer: Relationship with site of lesion
}

\author{
J Gustavo Zayas MD MSc ${ }^{1}$, Bruce K Rubin MEngr MD ${ }^{2}$, Ernest L York MD ${ }^{1}$, \\ Dale C Lien $\mathrm{MD}^{1}$, Malcolm King $\mathrm{PhD}^{1}$ \\ ${ }^{1}$ Pulmonary Research Group, University of Alberta, Edmonton, Alberta; \\ ${ }^{2}$ Wake Forest University Department of Pediatrics, Winston-Salem, North Carolina
}

JG Zayas, BK Rubin, EL York, DC Lien, M King. Bronchial mucus properties in lung cancer: Relationship with site of lesion. Can Respir J 1999;6(3):246-252.

OBJECTIVE: To compare the biophysical properties of mucus from the left and right mainstem bronchi in patients undergoing diagnostic bronchoscopy because of a unilateral radiological abnormality. It was hypothesized that abnormalities in the properties of mucus would be greater on the side with the lesion and that this would be most obvious in patients with unilateral lung cancer.

PATIENTS AND METHODS: Bilateral paired samples of bronchial mucus were taken from 38 nonatopic patients (aged 59.8 \pm 12.6 years) including 16 nonsmokers, 14 current smokers and eight exsmokers (more than one year). Twenty of the 38 patients had a radiologically defined unilateral abnormality. Eight of these 20, including one nonsmoker, had lung cancer. The viscoelastic properties of the collected mucus were determined by magnetic microrheometry, and the analysis was carried out without knowledge of the histological diagnosis or source.

RESULTS: The rheological properties of mucus strongly suggested which was the abnormal side. Within the group of 20 patients with a unilateral radiological abnormality, mucus from the side of the lesion had a lower value of the loss tangent, $\tan \delta 100(\mathrm{P}=0.004)$, indicating greater mucus recoil. This is consistent with poor mucus cough clearability on the lesion side. All eight cancer patients fit this mucus rheological pattern with a lower value of $\tan \delta 100$ on the affected side $(\mathrm{P}=0.007)$. Four of the five other patients with a similar mucus abnormality were categorized as high cancer risk by other criteria, while six of seven patients with mucus that did not have this abnormality were considered to be lower risk. Based on the mucus analysis done at the time of the bronchoscopy, two of the 'noncancer' patients initially designated as high risk had cancer detected after several months of followup. Only two of the 18 patients without a defined unilateral lesion fit the mucus 'cancer pattern'.

CONCLUSIONS: These findings are consistent with the hypothesis that either abnormalities in mucus properties may represent a risk factor for the development of lung cancer or that bronchial mucus abnormalities may be associated with products secreted by the tumours that, in turn, may suppress mucus clearance.

Key Words: Lung cancer; Lung tumours; Mucus; Smoking

\section{Propriétés du mucus bronchique dans le cancer du poumon : Lien avec le site de la lésion}

OBJECTIF : Comparer les propriétés biophysiques du mucus des bronches souches gauche et droite chez les patients subissant une bronchoscopie diagnostique à cause d'une anomalie radiologique unilatérale. Selon notre hypothèse, les anomalies dans les propriétés du mucus seraient plus importantes du côté de la lésion et ce

voir page suivante

Correspondence and reprints: Dr Malcolm King, Pulmonary Research Group - 173 HMRC, University of Alberta, Edmonton, Alberta T6G 2S2. Telephone 780-492-6703, fax 780-492-4878, e-mail malcolm.king@ualberta.ca 
phénomène serait plus apparent chez les patients atteints d'un cancer pulmonaire unilatéral.

PATIENTS ET MÉTHODES : Des échantillons bilatéraux appariés de mucus bronchique ont été prélevés sur 38 patients non atopiques (âgés de 59,8 $\pm 12,6$ ans) comprenant 16 non-fumeurs, 14 fumeurs, et 8 anciens fumeurs (plus d'un an). Vingt des 38 patients présentaient une anomalie unilatérale définie à la radiographie. Huit de ces 20 patients, y compris un non-fumeur, avaient un cancer du poumon. Les propriétés viscoélastiques du mucus recueilli ont été déterminées par micro-rhéométrie magnétique, et on a procédé à l'analyse sans la connaissance du diagnostic histologique ou de la source du cancer. RÉSULTATS : Les propriétés rhéologiques du mucus indiquaient fortement quel côté était anormal. Dans le groupe des 20 patients présentant une anomalie radiologique unilatérale, le mucus du côté de la lésion démontrait une valeur inférieure de la tangente de l'angle des pertes $(\tan \delta 100 ; \mathrm{p}=0,004)$, indiquant une plus grande rétraction du mucus. Ceci est compatible avec une clairance médiocre du mucus par la toux sur le côté de la lésion. Les huit patients atteints de cancer entrent dans ce schéma rhéologique du mucus avec une valeur inférieure de $\tan \delta 100 \mathrm{du}$ côté affecté $(p=0,007)$. Quatre des cinq autres patients présentant une anomalie similaire ont été catégorisés comme à risque élevé de cancer par d'autres critères, alors que six des sept patients dont le mucus ne présentait pas cette anomalie ont été considérés comme étant à risque moins élevé. Sur la base de l'analyse du mucus faite au moment de la bronchoscopie, chez deux des patients « non cancéreux » initialement considérés comme étant à haut risque, un cancer a été décelé après plusieurs mois de suivi. Seulement deux des 18 patients sans lésion unilatérale définie correspondent au « modèle cancéreux » de mucus.

CONCLUSIONS : Ces résultats s'accordent avec l'hypothèse que des anomalies des propriétés du mucus peuvent représenter un facteur de risque pour le développement d'un cancer ou que des anomalies du mucus bronchique peuvent être associées à des produits sécrétés par des tumeurs, qui à leur tour peuvent supprimer la clairance du mucus.
$\mathrm{M}$ any studies have shown that smoking leads to abnormalities in mucus clearance, both in humans (1-4) and in animals (5). We have demonstrated that canine mucus rheology is altered by cigarette smoke exposure, initially in a way that predictive equations suggest would increase mucociliary transportability (6). This alternation is relatively short-lived and disappears with continued smoke exposure. With longer exposure, there is an indication that biochemical changes occur in the mucous glycoprotein.

In two previous studies, we collected and analyzed tracheal mucus collected on a bronchoscopy brush from patients undergoing diagnostic bronchoscopy (7), or from the endotracheal tube of patients without signs or symptoms of lung disease who required elective nonpulmonary surgery (4). In both of these studies, symptom-free early tobacco smokers with 10 or fewer pack-years of smoking history had mucus that was less rigid and more easily cleared by cilia. This apparent advantage disappeared with continued exposure to tobacco smoke, and the mucus became progressively more difficult to clear by coughing.

More than 40 years ago, Hilding (8) suggested that abnormalities in ciliary streaming could lead to prolonged retention of carcinogens, increasing the risk of lung cancer. It has also been demonstrated that patients with chronic bronchitis and cancer have slower mucociliary clearance than patients with comparable lung function but no cancer (9).

Usually lung cancer occurs on one side; very rarely, it is bilateral. Because of this, we hypothesized that there may be unilateral alterations in the biophysical and transport properties of airway mucus that were greatest on the side with a radiologically defined lesion and that the difference between sides would be greatest in patients with cancer in the one lung. Alternatively, we thought that there might be consistent changes in mucus properties in both the cancerous and contralateral lung of cancer patients that would not observed in patients without cancer. Therefore, we collected mucus from the major airways of both lungs in patients with unilateral abnormalities undergoing diagnostic bronchoscopy, and compared mucus biophysical properties in both the involved and contralateral lungs, and in patients found to have lung cancer (on the basis of this diagnostic bronchoscopy) and those patients who did not have cancer.

\section{SUBJECTS AND METHODS}

Subjects: Forty-one subjects who underwent diagnostic bronchoscopy for various pulmonary abnormalities were studied. Subjects with obvious acute or chronic airway infections, ie, purulent sputum or fever, were excluded. The bronchoscopic procedure followed standard guidelines, with the exception that no atropine was administered until after the collection of the mucus sample for rheological analysis. Topical lidocaine was used as required for local anesthesia. The experimental protocol was approved by the University of Alberta Hospitals Medical Ethics Committee, and informed consent was obtained from all subjects.

Most subjects had pulmonary function testing, bronchoalveolar lavage, cytology and biopsy completed, in addition to the bronchoscopy, as part of their diagnostic workup. A detailed smoking history was obtained from all subjects.

Mucus collection: For mucus collection, the hypopharynx was anesthetized by topical application of $4 \%$ xylocaine without adrenalin, and a flexible bronchoscope was introduced. A cytology brush was placed in direct contact with the tracheal mucosa for about $20 \mathrm{~s}$, thus allowing for the collection of several microliters of mucus (10). A sample of mucus was collected from each mainstem bronchus. The side of first collection was randomly varied. The mucus collection took less than 5 mins and preceded any other bronchoscopic procedure. No anticholinergic premedication was given, but patients were given topical xylocaine to suppress coughing and bleeding from the sampling site.

As in previous studies, the mucus samples were removed from the brush and covered with paraffin oil to prevent mucus dehydration. The viscoelastic properties were determined by magnetic microrheometry within $1 \mathrm{~h}$ of collection. The mucus collection and rheological analysis were carried out without knowledge of the clinical history of the patient, diagnosis, site of collection or the order of collection.

Rheological analysis: The magnetic microrheometer technique consists of introducing a small steel sphere about 

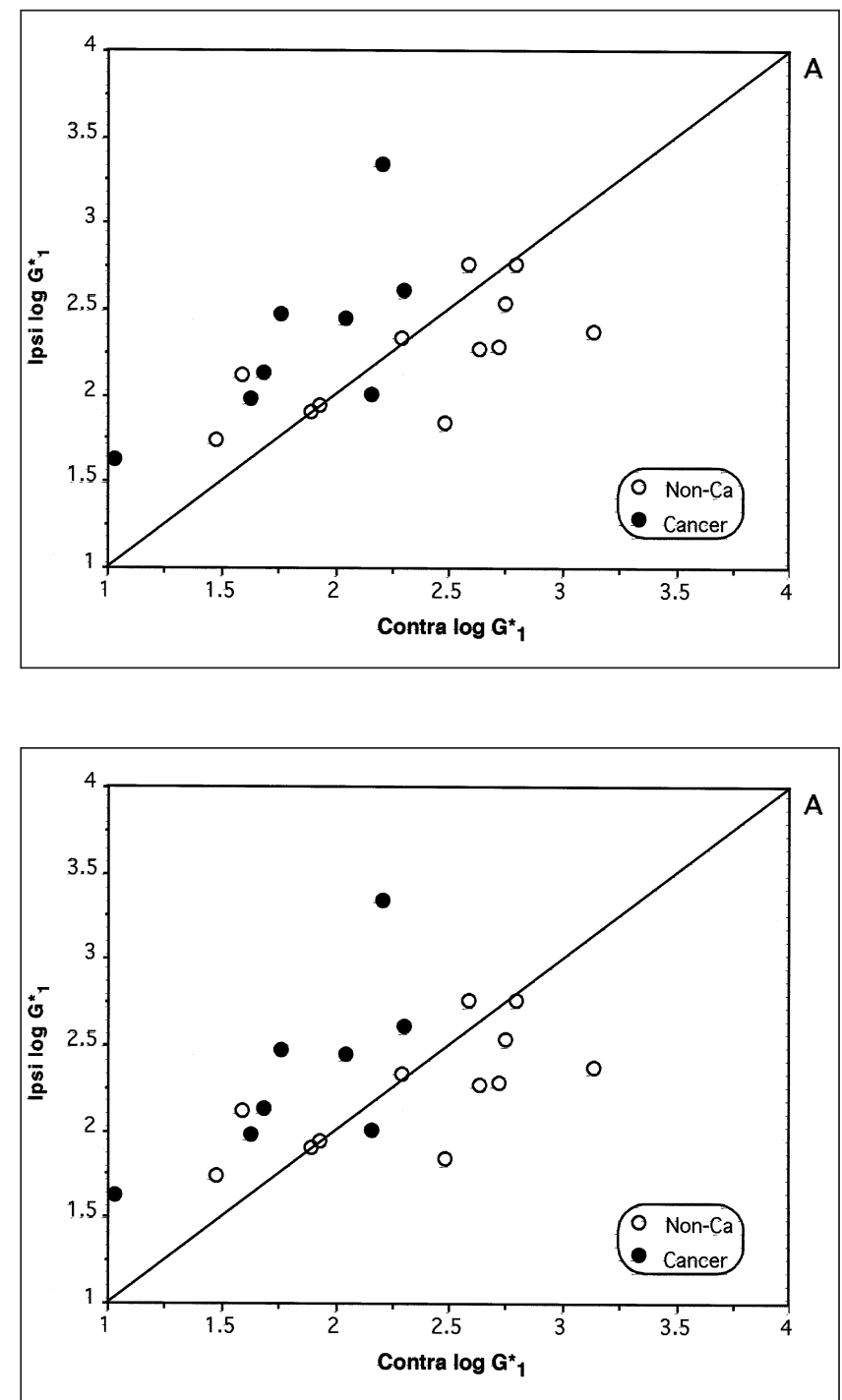

Figure 1) Comparisons of $\log G^{*}$ (rigidity factor at $1 \mathrm{rad} / \mathrm{s}$, top) and tan $\delta$ (recoil factor at $1 \mathrm{rad} / \mathrm{s}$, bottom) at low frequency for $\mathrm{mu}$ cus collected from the mainstem bronchi ipsilateral (lpsi) and contralateral (Contra) to a defined lesion. Ca Cancer

$100 \mu \mathrm{m}$ in diameter into the mucus. This sphere is oscillated in a magnetic field produced by alternating current. The displacement of the image of the ball is magnified by a microscope and detected by an optical system. The signals corresponding to ball displacement and magnetic force are displayed together on an oscilloscope, forming an ellipse corresponding to strain versus stress from which viscosity and elasticity can be determined. The method requires only microliter quantities of mucus (11).

Two viscoelastic parameters were studied; $G^{*}$ (mechanical impedance or 'rigidity') and $\tan \delta$ (loss tangent or the inverse of recoil). Each were measured at a frequency of 1 and $100 \mathrm{rad} / \mathrm{s}$. G* is the vector sum of elasticity and viscosity, and is a measure of the resistance to deformation or rigidity. Tan $\delta$ is the ratio of viscous to elastic deformation. A material with a high $\tan \delta$ deforms permanently when subjected to a stress or force; a material with a low $\tan \delta$ recoils or snaps
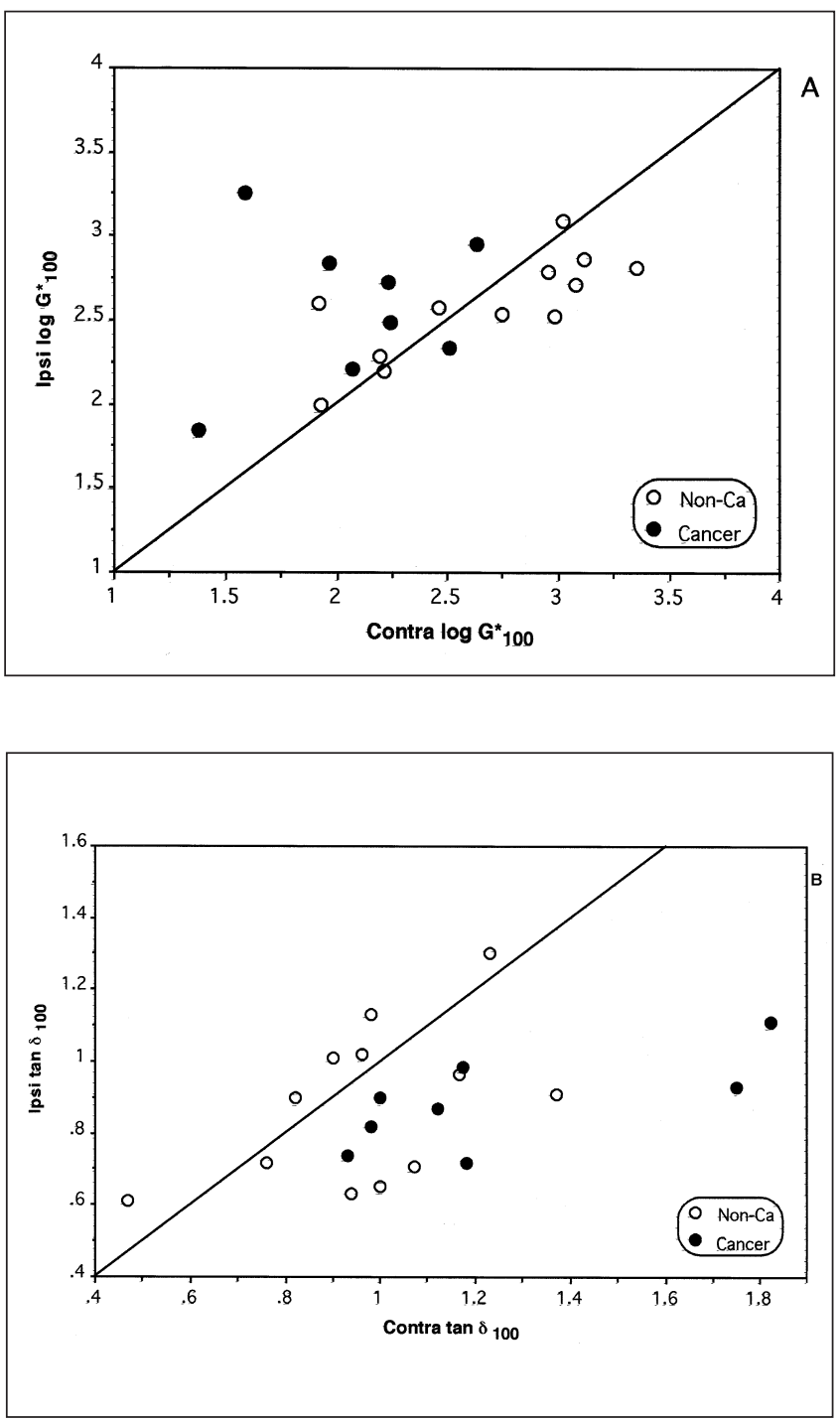

Figure 2) Comparisons of $\log G^{*}$ (rigidity factor at $100 \mathrm{rad} / \mathrm{s}$, top) and tan $\delta$ (recoil factor at $100 \mathrm{rad} / \mathrm{s}$, bottom), at high frequency for mucus collected from the mainstem bronchi ipsilateral (lpsi) and contralateral (Contra) to a defined lesion. Ca Cancer

back after the stress is removed (12). A mucociliary clearability index (MCI) was computed from $\mathrm{G}^{*}$ and $\tan \delta$ at $1 \mathrm{rad} / \mathrm{s}$, and a cough clearability index (CCI) was computed from $\mathrm{G}^{*}$ and $\tan \delta$ at $100 \mathrm{rad} / \mathrm{s}$ as previously described $(13,14)$. Both indexes relate negatively with the rigidity factor; MCI also relates negatively with the recoil factor, but $\mathrm{CCI}$ relates positively with it. Their respective formulas are as follows:

$$
\begin{gathered}
\mathrm{MCl}=1.62-0.22 \times \log \mathrm{G}^{*} 1 \mathrm{rad} / \mathrm{s}-0.77 \times \tan \delta 1 \mathrm{rad} / \mathrm{s}(\mathrm{I}) \\
\mathrm{CCl}=3.44-1.07 \times \log \mathrm{G}^{*} 100 \mathrm{rad} / \mathrm{s}+0.89 \times \tan \delta 100 \mathrm{rad} / \mathrm{s}(\mathrm{II})
\end{gathered}
$$

In vitro ciliary transportability: A mature northern leopard frog is pithed by bending the head forward and inserting an 18 gauge needle into the brain and the spinal cord. The jaw is disarticulated, and the palate is removed by cutting through from the junction of the posterior pharynx and esophagus out to the skin of the back. The excised palate is placed on a piece 

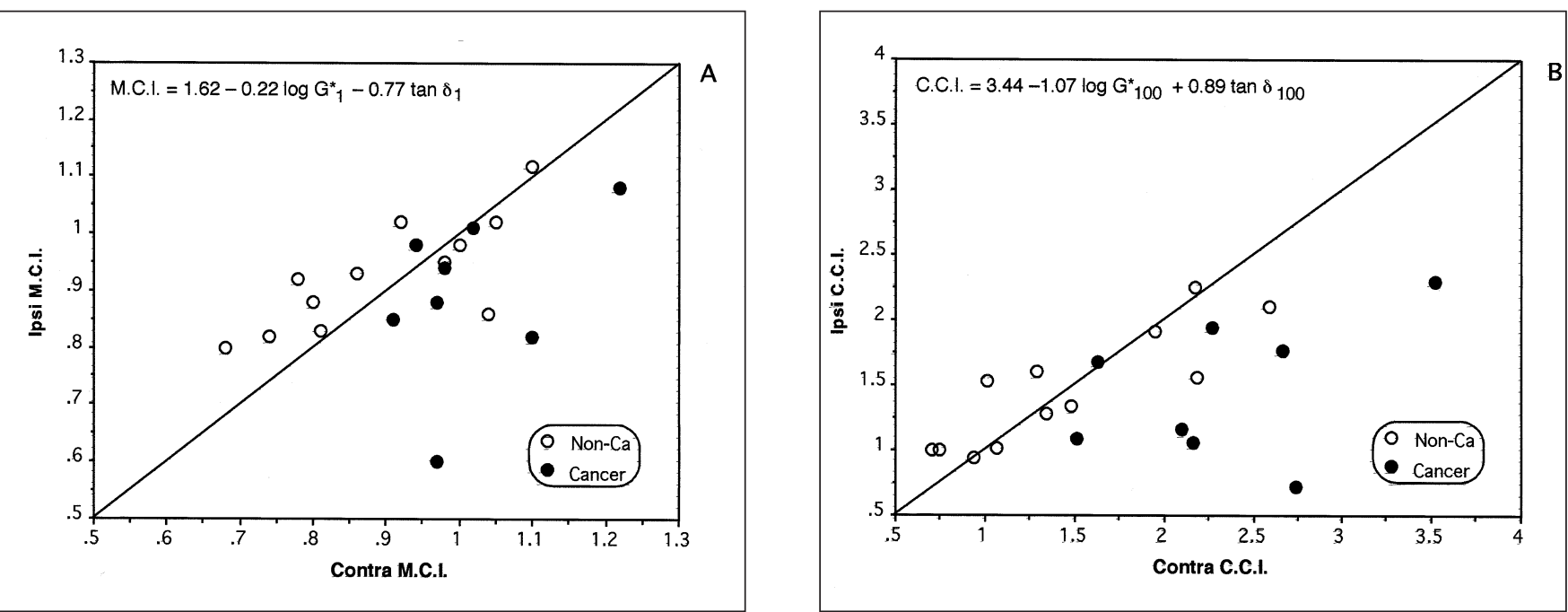

Figure 3) Comparisons of predicted mucociliary clearability (Equation 1, left) and cough clearability (Equation 2, right) of mucus collected from the mainstem bronchi ipsilateral (lpsi) and contralateral (Contra) to a defined lesion. Ca Cancer; CCI Cough clearability index; MCI Mucus clearability index

of gauze saturated with modified amphibian Ringer's solution prepared by mixing two parts of nonlactated Ringer's injection solution with one part sterile water. This gives a solution with an osmolarity of $206.5 \mathrm{mOsm} / \mathrm{L}$ containing (in $\mathrm{mmol} / \mathrm{L}$ ): sodium chloride 98.3 , potassium chloride 2.7 and calcium chloride 1.5 . The palate is placed in a dish loosely covered with plastic wrap and allowed to rest in a refrigerator at $4^{\circ} \mathrm{C}$ for 12 to $18 \mathrm{~h}$ to deplete the mucus.

The following morning, the palate is placed in a box with a fitted glass top. Humidity is maintained at $95 \%$ to $100 \%$ and temperature is kept at $22^{\circ} \mathrm{C}$ to $24^{\circ} \mathrm{C}$. The palate is placed under a microscope so that a $12.7 \mathrm{~mm}$ micrometer scale runs between the optic bulges to the opening of the esophagus. The movement of a 2 to $5 \mu \mathrm{L}$ sputum specimen is timed as the leading edge moves across a $7.62 \mathrm{~mm}$ segment. Three measurements of mucus transport rate are taken to minimize variability, and the average transport rate is normalized to the transport rate for collected endogenous frog mucus (15).

Mucus hydration - Percentage solids composition: The mucus samples were weighed, and, where sufficient quantity was available, the samples were evaporated to dryness in a microwave oven for 20 mins at 650 watts to determine the percentage solids content (inverse of hydration).

Data analysis: Data are reported as mean \pm SD unless otherwise stated. Intersite comparisons were based on paired twotailed $t$ tests. By convention, $\mathrm{P}<0.05$ was considered statistically significant. The statistical analysis was assisted by a personal computer program (StatView 5, SAS Institute Inc, Cary, North Carolina).

\section{RESULTS}

Paired samples of mucus suitable for rheological analysis were obtained from 38 of the 41 patients. The 38 patients included 16 nonsmokers, 14 current smokers and eight exsmokers (more than one year); mean age was 59.8 \pm 12.6 years. Twenty of the 38 patients had a radiologically definable lesion localized to one lung. Following the analysis of the data provided by the bronchoscopic procedure or the pathological examination of the biopsies taken, six of the 20 patients (four smokers, one exsmoker, one nonsmoker) were found to have lung cancer. During the subsequent two years, two more patients (both smokers) were found to have lung cancer on the basis of follow-up diagnostic procedures, giving a total of eight patients with lung cancer.

The rheological findings are summarized in Figures 1 and 2 , which show the rigidity factor and the recoil factor for the mucus determined at two different measurement frequencies. For the eight patients with cancer, the rigidity factor, $\log \mathrm{G}^{*}$, was generally greater on the side with cancer. This was true both at low frequency $(\mathrm{P}=0.008$, Figure $1 \mathrm{~A})$ and at high frequency $(\mathrm{P}=0.04$, Figure $2 \mathrm{~A})$. The recoil factor at low frequency (Figure 1B) did not distinguish cancer patients from those without cancer, but the same factor (recoil) at high frequency fell consistently on one side of the identity line for the eight subjects with lung cancer (Figure $2 \mathrm{~B}, \mathrm{P}=0.007$ ). This latter result indicates that the mucus in the lung ipsilateral with the cancerous lesion has a lower viscosity to elasticity ratio or greater elastic recoil than the mucus in the contralateral lung. According to equation (II) for CCI, based on model studies, the mucus from the side with cancer should be more difficult to clear by coughing. The remaining 12 patients without cancer of the 20 with a side definable lesion did not have mucus that was rheologically distinguishable by site of collection. This was also true of the 18 subjects without a side-definable lesion; in these patients, the intersite variation in $\tan \delta$ was generally less than $15 \%$, similar to the interbronchial variation seen in dogs. By way of comparison, in a comparable group of nonexposed dogs, the interbronchial variation in $\tan \delta$ at $100 \mathrm{rad} / \mathrm{s}$ was $18.3 \%$. In 19 paired mainstem bronchus mucus samples from dogs, no statistical differences among all the rheological parameters studied was observed.

The intersite variation in the two derived indexes of mucus clearability, MCI and CCI, is plotted in Figure 3. Both in- 


\section{TABLE 1}

Mucus quantity, percentage solids content, and normalized frog palate clearability (NFPC) (in vitro ciliary transportability)

\begin{tabular}{|c|c|c|c|}
\hline & $\begin{array}{l}\text { Weight of } \\
\text { mucus } \\
\text { collected (mg) }\end{array}$ & $\begin{array}{c}\text { Solids } \\
\text { content (\%) }\end{array}$ & NFPC \\
\hline \multicolumn{4}{|c|}{ Patients with cancer } \\
\hline $\begin{array}{l}\text { Ipsilateral } \\
\text { bronchus }\end{array}$ & $32.7 \pm 25.3(6)$ & $10.5 \pm 3.6(6)$ & $0.62 \pm 0.43(6)$ \\
\hline $\begin{array}{l}\text { Contralateral } \\
\text { bronchus }\end{array}$ & $11.0 \pm 7.2(5)$ & $11.9 \pm 6.5(5)$ & $0.92 \pm 0.48(6)$ \\
\hline$P$ & 0.035 & 0.48 & 0.28 \\
\hline \multicolumn{4}{|c|}{ Patients without cancer } \\
\hline $\begin{array}{l}\text { Ipsilateral } \\
\text { bronchus }\end{array}$ & $6.4 \pm 6.5(12)$ & $11.7 \pm 5.0(9)$ & $0.98 \pm 0.39(12)$ \\
\hline $\begin{array}{l}\text { Contralateral } \\
\text { bronchus }\end{array}$ & $8.2 \pm 8.0(12)$ & $14.3 \pm 5.1(9)$ & $0.91 \pm 0.50(12)$ \\
\hline$P$ & 0.48 & 0.18 & 0.32 \\
\hline
\end{tabular}

Data are mean $\pm S D$ with numbers of observations in brackets. Intersite comparisons are based on paired t tests

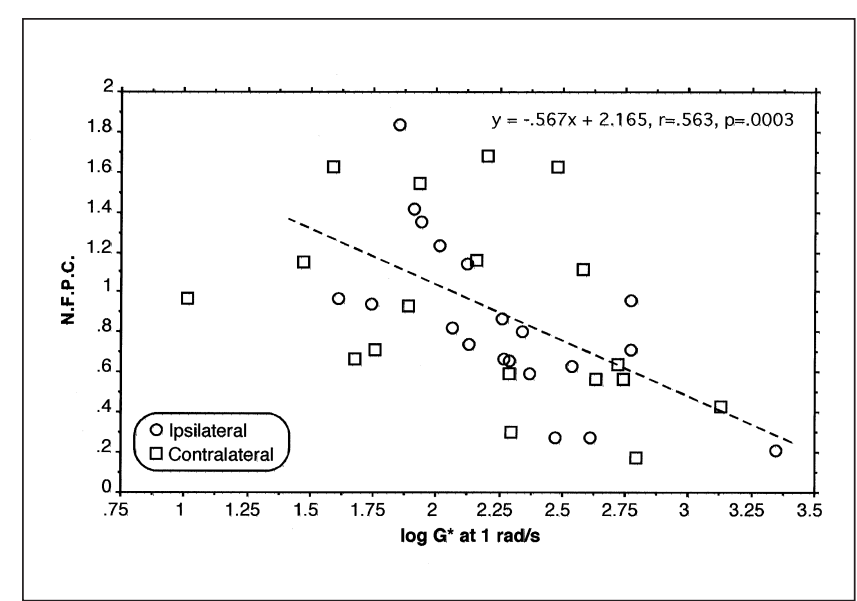

Figure 4) Relationship between normalized frog palate clearability $(N F P C)$ and mucus rigidity $\left(\log G^{*}\right.$ at $\left.1 \mathrm{rad} / \mathrm{s}\right)$. The mucus from the side ipsilateral to the lesion follows the same relationship as the mucus from the contralateral side. The data point representing the least rigid mucus sample was considered to be below the rheological optimum for ciliary transportability and was excluded from the correlation

dexes, which are based on combinations of rigidity and recoil, separated the cancer patients from those without cancer ( $\mathrm{P}=0.04$ for $\mathrm{MCI}$ and $\mathrm{P}=0.007$ for $\mathrm{CCI})$. In each case, the differences in predicted mucus clearability between the two lungs are consistent with slower clearance in the lung with the cancer.

There was a significantly greater mucus wet weight from the side with the lesion in the case of the cancer patients $(\mathrm{P}=0.04)$ (Table 1), consistent with pooling or retention of mucus in the affected bronchi. The percentage dry weight in the mucus from the lungs with cancer was marginally less than that from the contralateral lungs; this trend was the opposite of that expected, given the differences in rheology between the affected and unaffected sides. As shown in

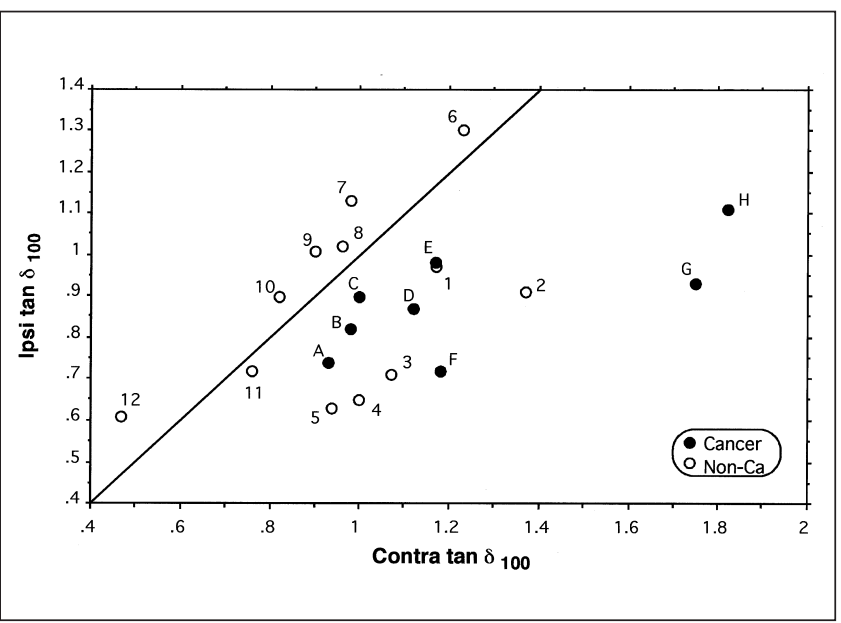

Figure 5) Comparison of high frequency recoil factor (tan $\delta$ at $100 \mathrm{rad} / \mathrm{s}$ ) for mucus collected from the mainstem bronchi ipsilateral (lpsi) and contralateral (Contra) to a defined lesion. The deviation from the line of identity for the cancer patients is significant $(P<0.007)$. The letters beside the filled circles indicate individual cancer patients, as described in Table 2. The numbers beside the open circles refer to individual patients without cancer (Non-Ca), as described in Table 3

TABLE 2

Characteristics of lung cancer patients in study

\begin{tabular}{|c|c|c|}
\hline Patient & Cancer type & Comments \\
\hline A & RUL adenocarcinoma II/III & $\begin{array}{l}\text { Diagnosis made three } \\
\text { months later }\end{array}$ \\
\hline B & LUL oat cell cancer & \\
\hline $\mathrm{C}$ & RLL small cell cancer & \\
\hline $\mathrm{D}$ & RML adenocarcinoma & $\begin{array}{l}1981 \text { right upper lobectomy } \\
\text { (adenocarcinoma) }\end{array}$ \\
\hline$E$ & $\begin{array}{l}\text { Left } \mathrm{Br} \text { squamous cell } \\
\text { cancer }\end{array}$ & $\begin{array}{l}\text { Radiotherapy for cancer } \\
1986\end{array}$ \\
\hline $\mathrm{F}$ & Right Br typical carcinoid & \\
\hline G & $\begin{array}{l}\text { LUL large cell anaplastic } \\
\text { cancer }\end{array}$ & $\begin{array}{l}\text { Nonsmoker, widespread } \\
\text { metastasis }\end{array}$ \\
\hline $\mathrm{H}$ & $\begin{array}{l}\text { Right squamous cell } \\
\text { cancer }\end{array}$ & $\begin{array}{l}\text { Diagnosis made } 20 \text { months } \\
\text { later, metastatic to both } \\
\text { lungs }\end{array}$ \\
\hline
\end{tabular}

$\overline{\text { Br Bronchus; LUL Left upper lobe; RLL Right lower lobe; RML Right }}$ middle lobe; RUL Right upper lobe

Table 1, the frog palate assay of mucociliary transportability was consistent with the rheological findings that suggested decreased ciliary clearability on the lesion side, but the differences did not achieve statistical significance. Overall, there was a significant correlation between normalized frog palate clearability and mucus rigidity (normalized frog palate clearability versus $\log \mathrm{G}^{*}$ at $1 \mathrm{rad} / \mathrm{s}: \mathrm{r}=0.56, \mathrm{P}=0.0003$ ), as well as between observed and predicted clearability (Normalized frog palate clearability versus MCI: $r=0.54$, $\mathrm{P}=0.0006$ ). The relationship between the frog palate assay of ciliary transportability and the rigidity of the collected mucus is illustrated in Figure 4.

There was no consistent variation in rheological properties between the first and second sample taken, nor between 
TABLE 3

Characteristics of noncancer patients in study

\begin{tabular}{lllcll}
\hline Patient & Smoking & Diagnosis/pathology & $\begin{array}{c}\text { Mucus cancer } \\
\text { pattern }\end{array}$ & $\begin{array}{l}\text { Cancer } \\
\text { risk }\end{array}$ & Comments \\
\hline 1 & Nonsmoker & Right upper lung infiltrate & $\checkmark \checkmark$ & High & Benign tumour right lung, resected in 1955 \\
2 & Exsmoker & $\begin{array}{l}\text { Right lower lung nodule } \\
\text { Right lower lung } \\
\text { hyperplasia }\end{array}$ & High & Uranium worker \\
Hamartoma diagnosed later
\end{tabular}

Two patients $(A$ and $H)$ originally classified as "high risk" were later diagnosed with lung cancer, and transferred to the lung cancer patient group (Table 2). $\checkmark$ Recoil factor ipsilateral greater than contralateral; $\checkmark \checkmark$ Recoil factor ipsilateral much greater than contralateral; $\times$ Recoil factor ipsilateral approximately equal to contralateral

the right and left sides in patients without side-definable lesions. The rheological properties of mucus from the mainstem bronchi were comparable with the properties of tracheal mucus samples obtained from patients with similar smoking histories $(4,7)$.

A more detailed analysis of the recoil factor at $100 \mathrm{rad} / \mathrm{s}$ is given in Figure 5. Of the eight patients with lung cancer, one $(\mathrm{G})$ was a nonsmoker. Two patients $(\mathrm{A}$ and $\mathrm{H})$ were only diagnosed with cancer upon follow-up diagnostic procedures, in one case three months after the original bronchoscopy, and the other 20 months later. Details are given in Table 2.

The mucus rheological pattern seen in patients with cancer consisted of a greater than $15 \%$ difference in $\tan \delta 100$ between the two sides sampled with the lower $\tan \delta 100$ on the side with cancer. Five of the 13 patients with a side-definable lesion but no cancer had a mucus pattern consistent with this, and four of the five were considered to have an elevated risk of developing lung cancer. In addition, the two patients who either subsequently developed cancer or in whom cancer was only detected later fit this rheological risk pattern. The major criteria for risk level were cigarette smoke exposure, size of the radiological lesion, pathological changes of the airway cells and exposure to established carcinogenic factors such as uranium. Minor criteria included a familiar history of lung cancer. Characteristics of these patients are shown in Table 3. Six of the remaining seven patients who did not show these mucus rheological characteristics were described as being at lower risk of developing lung cancer, although, given the fact that they underwent an indicated bronchoscopy, the assignment of risk must be considered relative.

\section{DISCUSSION}

Hilding (8) first suggested that alterations in mucociliary clearance might allow carcinogens to be retained in the lung longer than usual, thereby prolonging their action. He also mapped the distribution of lung cancer according to this hypothesis, a distribution that matched reasonably well with the more frequent sites of neoplastic transformation. Auerbach and co-workers (16) presented evidence that confirmed that the anatomical lesions in airway epithelium after cigarette smoke exposure in dogs follow this anatomic distribution.

The long process of lung cancer development makes it very difficult to undertake a prospective study to test the hypotheses that changes in mucus clearance due to abnormal mucus rheology enhance the possibility of developing lung cancer or that tissue that has become cancerous produces abnormal mucus. In humans, smoking-related changes in the airway are both dose-related to the level of cigarette exposure and progress over approximately 30 to 40 years. Furthermore, there are no reliable animal models of tobacco smoke exposure to track the development of lung cancer. However, tobacco smoke exposure does produce airway changes in animals that may be preneoplastic.

We have shown changes in the biochemical composition of the mucus of dogs exposed to cigarette smoke, particularly the galactose content used as a marker of the mucus glycoprotein content (6). The fall in galactose content occurred at a very early stage and simultaneously with a similar fall in mucus rigidity. With continued smoke exposure, the rigidity of the mucus returned to normal values, while the galactose content remained at the same lower level. The prolonged decrease in galactose content in dogs exposed was interpreted 
as a change in the nature of the mucus. In humans, we previously demonstrated an almost identical pattern regarding a fall in mucus rigidity with an eventual return to normal values $(4,7)$. It is tempting to assume that a similar biochemical change in mucus composition might have happened in these subjects as well. Indeed, Basbaum and Jany (17) have shown that airway irritants such as tobacco smoke can modulate the biosynthesis of airway secretions as well as the induction of enzymes. In biochemical terms, this may involve the upregulation of mucin production, or an alteration in the mucin gene profile leading to the enrichment in gene products of greater chain length or content of cysteine residues (18).

Data in this study are consistent with earlier work. We have again demonstrated alterations in both mucus ciliary and cough clearability, apparently as a consequence of prolonged smoking. Although observed rheological alterations alone did not permit us to identify unequivocally patients with lung cancer, when used in combination with clinical risk factors, we were able to match the pathological reports closely. Most striking was that two patients, who did not have cancer diagnosed at the initial bronchoscopy when mucus was collected for analysis, but who were considered to have mucus rheological properties consistent with lung cancer based on the results of this study, were subsequently diagnosed with lung cancer after a second biopsy was obtained months later.

Some researchers have found increased alterations in mucociliary clearance rate in patients with lung carcinoma compared with patients without lung cancer matched for cigarette consumption and pulmonary function. They also reported that mucociliary clearance is even lower on the tumour side. The finding in the present study that mucus on the

\section{REFERENCES}

1. Goodman RM, Yergin BM, Landa JF, Golinvaux MH, Sackner MA. Relationship of smoking history and pulmonary function tests to tracheal mucous velocity in non-smokers, young smokers, ex-smokers, and patients with chronic bronchitis. Am Rev Respir Dis 1978;117:205-14.

2. Vastag E, Matthys H, Zsamboki G, Köhler D, Daikeler G. Mucociliary clearance in smokers. Eur J Respir Dis 1986;68:107-13.

3. Rubin BK, King M. The physiologic effects of smoking in COPD. J Respir Dis 1993;14:S19-25.

4. Rubin BK, Ramirez O, Zayas JG, Finegan B, King M. Respiratory mucus from asymptomatic smokers is better hydrated and more easily cleared by mucociliary action. Am Rev Respir Dis 1992;145:545-7.

5. Wanner A, Hirsch JA, Greeneltch DE, Swenson EW, Fore T. Tracheal mucous velocity in beagles after chronic exposure to cigarette smoke. Arch Environ Health 1973;27:370-1.

6. King M, Wight A, DeSanctis GT, et al. Mucus hypersecretion and viscoelastic changes in cigarette-smoking dogs. Exp Lung Res 1989; $15: 375-89$

7. Zayas JG, Man GCW, King M. Tracheal mucus rheology in patients undergoing diagnostic bronchoscopy: Interrelations with smoking and cancer. Am Rev Respir Dis 1990;141:1107-13.

8. Hilding AC. Ciliary streaming in the bronchial tree and the time element in carcinogenesis. N Engl J Med 1957;256:634-40.

9. Matthys H, Vastag E, Köhler D, Daikeler G, Fischer J. Mucociliary lesion side was rheologically inappropriate for efficient clearance is, thus, consistent with the observation of Matthys et al (9).

Abnormalities in both of the clearability parameters were seen in most patients with lung cancer, and these findings can be considered as evidence to support the hypothesis that prolonged retention of carcinogens due to inadequate clearance of mucus may lead more easily to the development of cancer. Neither parameter was distinctive for lung cancer because there was a degree of overlap with the population that did not have cancer. It is tempting to speculate, however, that the patients who have mucus inappropriate for clearance will be future targets for the development of cancer if they are exposed unnecessarily to carcinogens.

Our results do not allow us to determine whether the development of inappropriate mucus that appears to distinguish patients with lung cancer occurred before or subsequent to the initiation of the cancer. If the inappropriate mucus predated the cancer, the findings would be strong evidence for the initial hypothesis, ie, that prolonged retention of carcinogens due to abnormalities in mucus clearance could be a contributing factor to carcinogenesis. On the other hand, if the inappropriate mucus developed concurrently with or subsequent to the initiation of the cancer, the finding of a rheological abnormality would at best merely represent an early, and nonspecific, indicator of cancer. Only further studies on a much larger scale will enable us to distinguish between these two possibilities.

ACKNOWLEDGEMENTS: This study was supported by Medical Research Council of Canada; Dr JG Zayas-Zamora was the recipient of a Candian Lung Association Fellowship.

clearance in patients with chronic bronchitis and bronchial carcinoma. Respiration 1983;44:329-37.

10. Jeanneret-Grosjean A, King M, Lioté H, Michoud MC, Amyot R. Sampling technique and rheology of human bronchial mucus. Am Rev Respir Dis 1988;137:707-10.

11. King M, Macklem PT. The rheological properties of microliter quantities of normal mucus. J Appl Physiol 1977;42:797-802.

12. King M, Rubin BK. Rheology of airway mucus: Relationship with clearance function. In: Takashima T, Shimura S, eds. Airway Secretion: Physiological Bases for the Control of Mucus Hypersecretion. New York: Marcel Dekker, 1994:283-314.

13. King M. Relationship between mucus viscoelasticity and ciliary transport in guaran gel/frog palate model system. Biorheology 1980; $17: 249-54$

14. King M, Brock G, Lundell C. Clearance of mucus by simulated cough. J Appl Physiol 1985;58:1776-82.

15. Rubin BK, Ramirez O, King M. Mucus-depleted frog palate as a model for the study of mucociliary clearance. J Appl Physiol 1990;69:424-29.

16. Auerbach O, Hammond EC, Kirman BS, Garfinkle L, Stout AP. Histologic changes in bronchial tubes of cigarette smoking dogs. Cancer 1967;20:2055-66.

17. Basbaum C, Jany B. Plasticity in the airway epithelium. Am J Physiol 1990;259:38-46.

18. Rose MC, Gendler SJ. Airway mucin genes and gene products. In: Rogers DF, Lethem MI, eds. Airway Mucus: Basic Mechanisms and Clinical Perspectives. Basel: Birkhäuser, 1997:41-66. 


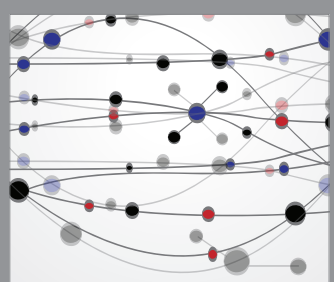

The Scientific World Journal
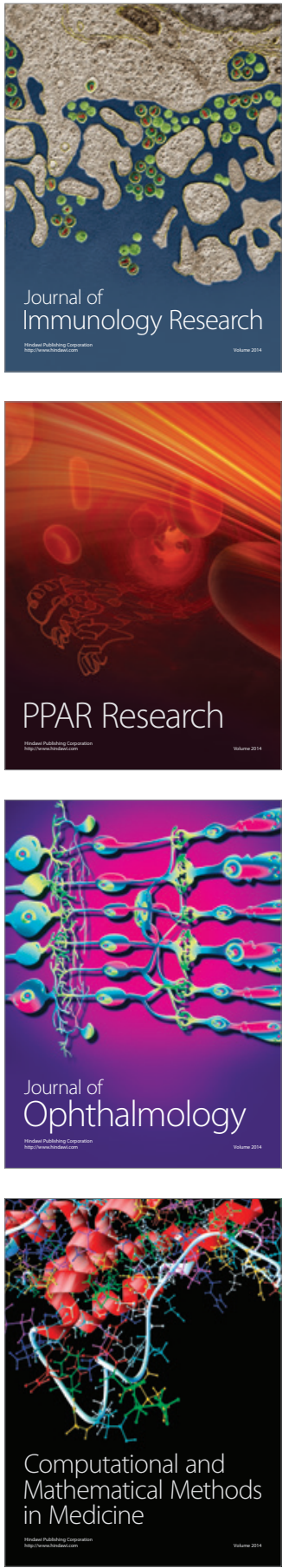

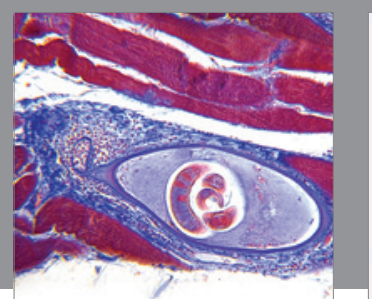

Gastroenterology Research and Practice

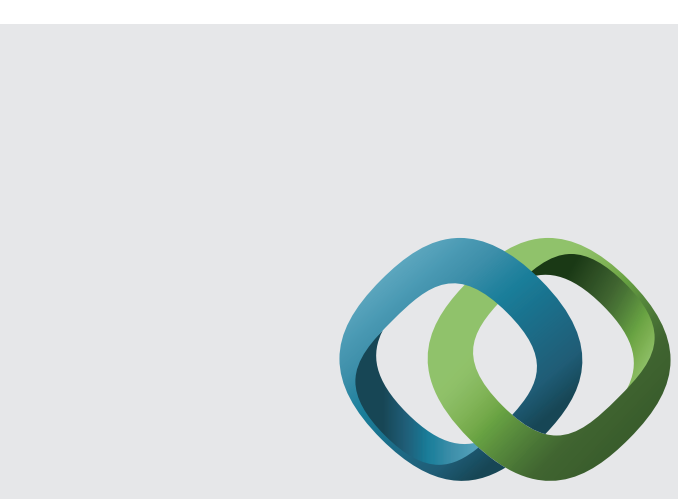

\section{Hindawi}

Submit your manuscripts at

http://www.hindawi.com
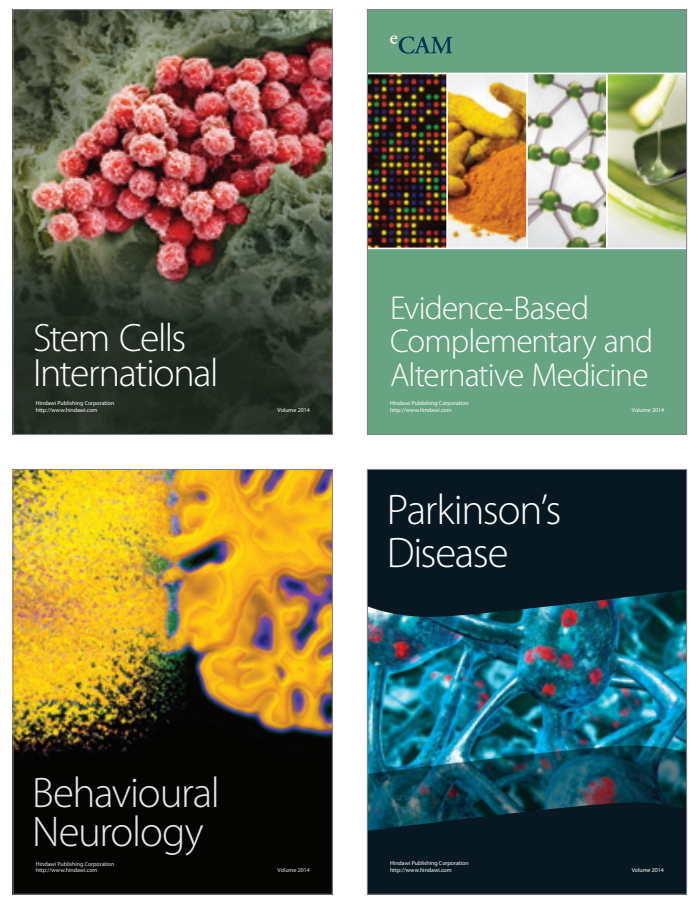
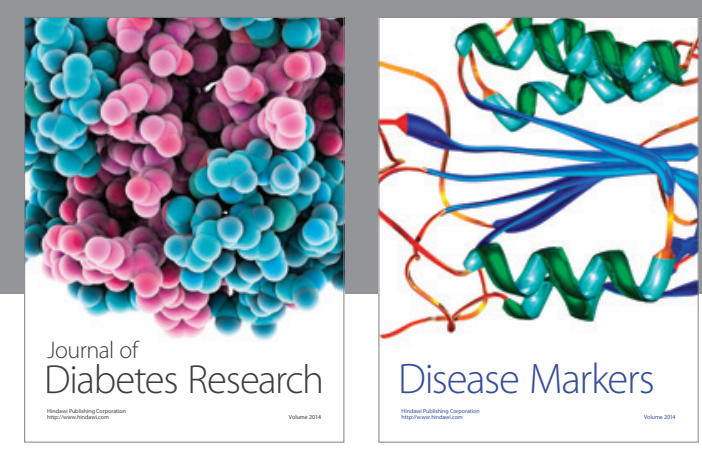

Disease Markers
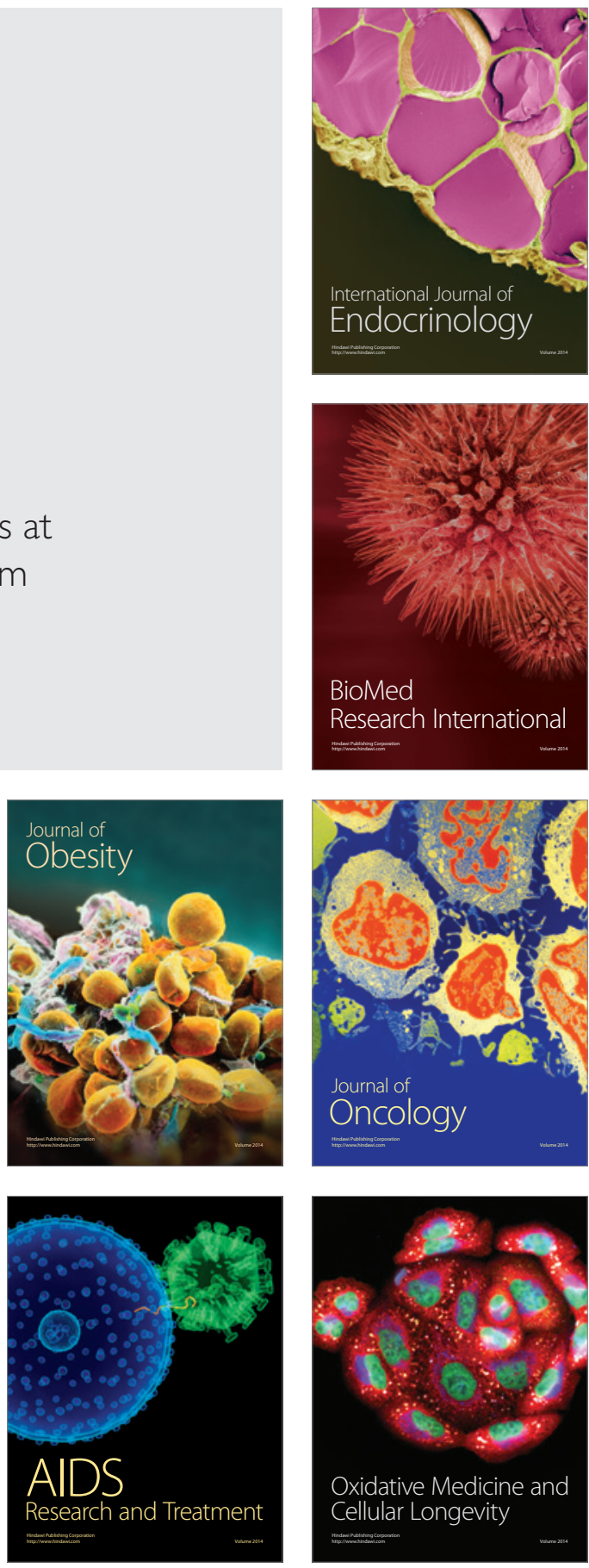